\title{
Synthesis of zinc borate by inverse emulsion technique for lubrication
}

\author{
Sevdiye Atakul Savrık • Devrim Balköse • \\ Semra Ülkü
}

Received: 21 June 2010/ Accepted: 3 November 2010/Published online: 12 December 2010

(C) Akadémiai Kiadó, Budapest, Hungary 2010

\begin{abstract}
Lubricating oil additives based on boron compounds are promising materials for lubrication due to their tribological advantages such as antiwear efficiency, good film strength, and high temperature resistance. This article deals with the preparation of zinc borate particles that are well dispersed and colloidally stabilized in mineral oil. This method starts with preparing two inverse emulsions (water-in-oil) with sorbitan monostearate (Span 60) as a surfactant, light neutral oil as a continuous phase, and the aqueous solutions of borax decahydrate $\left(\mathrm{Na}_{2} \mathrm{~B}_{4} \mathrm{O}_{7} \cdot 10 \mathrm{H}_{2} \mathrm{O}\right)$ and zinc nitrate $\left(\mathrm{Zn}\left(\mathrm{NO}_{3}\right)_{2} \cdot 6 \mathrm{H}_{2} \mathrm{O}\right)$ as the dispersed phases. The produced particles were zinc borate crystals having both rod-like and spherical morphologies, and the diameters of spherical particles were changing between 20 and $30 \mathrm{~nm}$. FTIR spectra of the obtained particles showed the characteristic peaks of trihedral borate (B(3)-O) and tetrahedral borate (B(4)-O) groups as well as the specific peaks of the sorbitan monostearate. TG showed $30.42 \%$ and $22.08 \%$ mass loss at $600{ }^{\circ} \mathrm{C}$ for the samples prepared by inverse emulsion and precipitation techniques, respectively. The endothermic peak at $50{ }^{\circ} \mathrm{C}$ is observed due to the melting of sorbitan monostearate and the heat of melting is evaluated as $-3.50 \mathrm{~J} / \mathrm{g}$. Tribological studies revealed that sorbitan monostearate not only outperformed as a dispersing agent of inorganic particles, but also it proved to be an anti-wear agent. Zinc borate produced by precipitation decreased the wear scar diameter from 1.402
\end{abstract}

S. A. Savrik $(\bowtie) \cdot$ D. Balköse · S. Ülkü

Department of Chemical Engineering, Izmir Institute

of Technology, Gülbahçe Köyü, 35430 Urla, Izmir, Turkey

e-mail: sevdiye.savrik@akzonobel.com

Present Address:

S. A. Savrik

Akzo Nobel Powder Coatings, Izmir, Turkey to $0.639 \mathrm{~mm}$ and the friction coefficient from 0.099 to 0.064 . The inverse emulsion was effective in decreasing wear scar diameter and the friction coefficient by lowering them to 0.596 and $0.089 \mathrm{~mm}$, respectively.

Keywords Zinc borate - Inverse emulsion - Lubrication · Dehydration

\section{Introduction}

The interest in the production of zinc borate has steadily grown because of the great expectations for the applications including polymer additive as flame retardants, the preservative in wood composites and additive for lubrication [1-5]. There have been different crystalline forms of hydrated zinc borate which can be prepared selectively using either borax and soluble zinc salt or boric acid and zinc oxide. The traditional production method is precipitation technique in aqueous media. Micron-sized zinc borate species are formed by precipitation technique and they have some limitations in their applications, notably in the lubricating oils. Micron-sized particles have lower dispersion property than nano-sized particles due to the agglomeration. In order to produce nanoparticles, a variety of the methods which are precipitation, hydrothermal treatment, spray drying, spray thermal decomposition, freeze drying, the microemulsion method, the phase transfer technique, and supercritical fluid drying methods are developed. Among the different techniques, the formation of inorganic species in inverse microemulsion environment has received special interest since it allows the preparation of ultrafine particles within the size range $5-50 \mathrm{~nm}$ and it is simple, safe and can produce regularly shaped particles with a narrow size distribution [6-8]. 
Inverse-emulsion based technique for the synthesis of inorganic particles is based on the assumption that the inner aqueous pool serves a confined micro-reactor for the production of desired particles [9]. Up to now, various kinds of particles have been successfully formed by using this technique including metal oxides and inorganic materials $[2,7,10]$.

The dispersion stability of nano-sized particles in base oil provides the system to be used as a lubricant. With the help of lubricants, the contact zones of moving parts can not come in direct contact with each other and the lubricants prevent the increase in temperature causing adhesion, scuffing, or even welding [11]. In literature many studies were conducted for the preparation of nano-sized metal borates by supercritical fluid drying technique and the dispersion of these species in the base oil by using sorbitan monostearate surfactant [12-14]. In these published articles, special attention has been paid to the tribological properties of the produced borate species and it was claimed that nano-sized metal borate species had significant role in reducing friction and wear properties when added into base oils. However, the lubricating property of the surfactant was not considered and the characterization of the metal borates was not completed in these studies [12-14]. The lubricating ability of sorbitan monolaurate and ethoxylated sorbitan monolaurate in paraffin oil were verified and as compared to paraffin oil, wear scar diameter was reduced four times, while the friction coefficient was reduced six times as reported by Wasilewski and Sulek [15]. In lubricant production mineral oil and biobased oils can be used. Moringa oil was proved to be an efficient lubricant base oil [11].

This study attempts to prepare nano-size zinc borate that can be used in lubricating additive by inverse emulsion technique and to characterize both the emulsions and zinc borate particles. Also it aims to present a new lubricant preparation technique in the field of both colloidal systems and nano-size particle preparation.

\section{Experimental}

\section{Materials}

Water-in-oil emulsions were prepared from aqueous solutions of borax decahydrate (Etibor), zinc nitrate hexahydrate $\left(\mathrm{Zn}\left(\mathrm{NO}_{3}\right)_{2} \cdot 6 \mathrm{H}_{2} \mathrm{O}\right)$ (Sigma-Aldrich), light neutral oil (TÜPRAŞ A.Ş.), and sorbitan monostearate (Span 60, Sigma-Aldrich). The precipitates of the emulsion products were washed with deionized water, methyl ethyl ketone (MEK) (Kimetsan), and ethanol (Riedel-de Haën). Zinc borate synthesized by precipitation technique was also prepared by borax decahydrate (Etibor), zinc nitrate hexahydrate $\left(\mathrm{Zn}\left(\mathrm{NO}_{3}\right)_{2} \cdot 6 \mathrm{H}_{2} \mathrm{O}\right)$ (Sigma-Aldrich), and sorbitan monostearate (Span 60, Sigma-Aldrich). Zinc borate prepared in this study and Firebreak 2335 from US Borax with composition $2 \mathrm{ZnO} \cdot 3 \mathrm{~B}_{2} \mathrm{O}_{3} \cdot 3 \mathrm{H}_{2} \mathrm{O}$ were also tested as anti-wear additives in the lubricants.

Preparation of inverse emulsions

Two-inverse emulsions technique was used to obtain zinc borate emulsion. Borax decahydrate and zinc nitrate emulsions were prepared at $70{ }^{\circ} \mathrm{C}$ by using a rotor-stator homogenizer combined 700 Watt with a rotor-stator generator probe of $10 \mathrm{~mm}$ diameter (OMNI GLH) and a magnetic stirrer (Yellowline MSH Basic) for 2 min and $2 \mathrm{~h}$, respectively. The mixing rates of the homogenizer and the magnetic stirrer were 13500 and $1000 \mathrm{rpm}$, respectively. Emulsion I was prepared by mixing $5 \mathrm{~cm}^{3} 1 \mathrm{~mol} /$ $\mathrm{dm}^{3}$ zinc nitrate in water with $50 \mathrm{~cm}^{3}$ light neutral oil having $0.5 \mathrm{~g}$ sorbitan monostearate, and emulsion II was prepared by mixing $5 \mathrm{~cm}^{3} 1 \mathrm{~mol} / \mathrm{dm}^{3}$ borax decahydrate in water with $50 \mathrm{~cm}^{3}$ light neutral oil having $0.5 \mathrm{~g}$ sorbitan monostearate. When emulsions I and II were mixed together at $70{ }^{\circ} \mathrm{C}$ with the homogenizer for $2 \mathrm{~min}$ and magnetic stirrer for $2 \mathrm{~h}$, zinc borate crystals were formed in water phase and dispersed in light neutral oil.

The water content of the inverse emulsions was removed since the water caused harmful corrosion effects on substrates in lubrication systems. The removal of water in zinc borate emulsions was accomplished by water-oil separation apparatus as shown in Fig. 1 [16]. The emulsion was heated up to $160{ }^{\circ} \mathrm{C}$ by mixing with $1000 \mathrm{rpm}$, and the accumulation of water was achieved in the condenser. The particles were separated from the oil by using a membrane

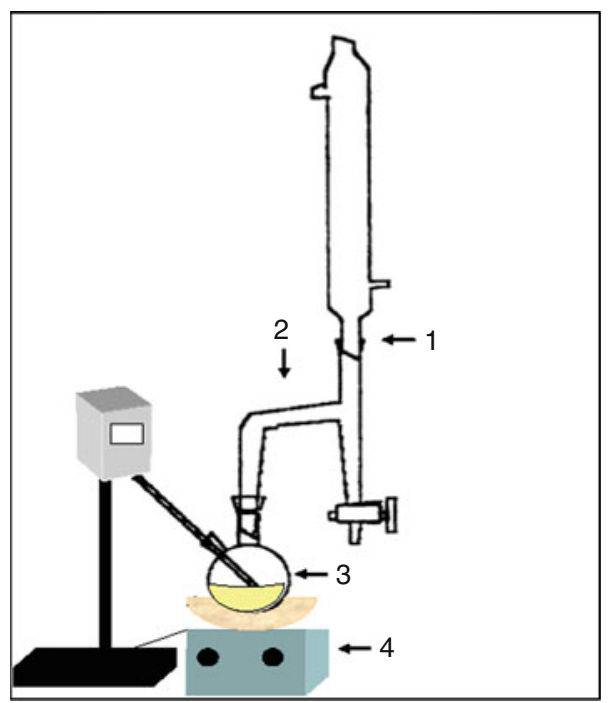

Fig. 1 Water-oil separation apparatus. 1 condenser, 2 distilling link, 3 flask, and 4 heater 
separation unit to characterize the zinc borate formed in the light neutral oil. Then, they were washed with $15 \mathrm{~cm}^{3}$ methyl ethyl ketone, $25 \mathrm{~cm}^{3}$ water, and $25 \mathrm{~cm}^{3}$ ethanol. Finally, the obtained particles were dried at $110{ }^{\circ} \mathrm{C}$ for $2 \mathrm{~h}$ in air circulating oven.

Preparation of zinc borate by precipitation technique

Zinc borate was prepared by mixing equal volumes $\left(50 \mathrm{~cm}^{3}\right)$ of $1 \mathrm{~mol} / \mathrm{dm}^{3}$ borax decahydrate and $1 \mathrm{~mol} / \mathrm{dm}^{3}$ zinc nitrate hexahydrate solutions and $1 \mathrm{~g}$ sorbitan monostearate. It was mixed at $70{ }^{\circ} \mathrm{C}$ by the homogenizer and magnetic stirrer for $2 \mathrm{~min}$ and $2 \mathrm{~h}$, respectively. The separation of particles from the aqueous media was achieved by using a membrane separation unit, then, the particles were washed with $50 \mathrm{~cm}^{3}$ water for three times and they were dried at $110{ }^{\circ} \mathrm{C}$ for $2 \mathrm{~h}$ in air circulating oven.

\section{Preparation of lubricants}

Lubricants were prepared by adding $1 \mathrm{~g}$ zinc borate to $100 \mathrm{~cm}^{3}$ light neutral oil having $1 \mathrm{~g}$ sorbitan monostearate and mixing at $70{ }^{\circ} \mathrm{C}$ for $2 \mathrm{~min}$ with homogenizer, for $2 \mathrm{~h}$ with magnetic stirrer at $160{ }^{\circ} \mathrm{C}$. Firebreak 2335 $\left(3 \mathrm{ZnO} \cdot 3 \mathrm{~B}_{2} \mathrm{O}_{3} \cdot 3 \mathrm{H}_{2} \mathrm{O}\right)$ and the zinc borate prepared by precipitation method in this study were used as lubricant additives. Mineral oil and the inverse emulsion heated up to $160{ }^{\circ} \mathrm{C}$ and mineral oil having 1 mass\% sorbitan monostearate were also tested as lubricants.

\section{Characterization}

Fourier Transform Infrared Spectrometer (Shimadzu 8601) was used to determine the chemical structure of the zinc borate species and sorbitan monostearate. $\mathrm{KBr}$ pellets were prepared by mixing $4.0 \mathrm{mg}$ of zinc borate or sorbitan monostearate and $196 \mathrm{mg}$ of $\mathrm{KBr}$ in an agate mortar and pressing the mixture under 8 tons. Thermal gravimetric analyses (TG) were performed using Shimadzu TGA-51. The samples (10-15 mg) were loaded into an alumina pan and heated from room temperature up to $600{ }^{\circ} \mathrm{C}$ at $10^{\circ} \mathrm{C} /$ min under $\mathrm{N}_{2}$ flow of $40 \mathrm{~cm}^{3} / \mathrm{min}$. DSC was performed on a calorimeter (Shimadzu, DSC 50). Dry powder (5-10 mg) was placed in an aluminum pan, and the samples were heated from room temperature up to $600{ }^{\circ} \mathrm{C}$ at a rate of $10{ }^{\circ} \mathrm{C} / \mathrm{min}$. SEM (Philips XL30 SFEG) images were employed to examine the morphology of the samples. CHNS elemental analysis (Leco Corporation St. Joseph MI, USA) was used to determine the elemental composition of the samples. XRD was performed using a X-ray diffractometer (Philips Xpert-Pro). The incident $\mathrm{CuK} \alpha$ radiation with $0.154 \mathrm{~nm}$ was used in the analysis. The measured XRD pattern was compared with those in the JPDS database. Besides the characterization of the samples, the emulsion characterization was carried out in an optical microscope (Olympus CX31), and the photographs were taken by a camera (Olympus DP25). Olympus DP2BSW program evaluated the diameters of the particles and the droplets. Surface tension of sorbitan monostearate was measured by KRÜSS Digital tensiometer (K1OST). Furthermore, tribological characterization of the lubricant containing zinc borate was performed by a four-ball wear test machine (made by Falex Corp.). Test balls were chrome alloy steel, made from AISI standard steel No. E52100 with a diameter of $12.7 \mathrm{~mm}$. The test was performed according to ASTM D 4172-94 at $392 \mathrm{~N}$ and the test duration was $1 \mathrm{~h}$. In addition, the worn surfaces of the balls run in the oil and the oil with additives were visualized by SEM (Philips XL30 SFEG).

\section{Results and discussion}

The morphology of emulsions

In inverse emulsions, oil diffusion is high, water diffusion as well as the surfactant mass transfer is low and corresponds to smaller water droplets than oil droplets [16]. The required particles were produced inside these water droplets since inverse micelles act as reactors. In this study, the morphological study was performed not only to investigate the morphology of the emulsions, but also to determine the particle size of the emulsions. The inverse emulsions were stabilized with sorbitan monostearate having HLB value 4.7 and this made the surfactant suitable for inverse systems. The surface tension of $1 \mathrm{~g}$ of this surfactant in $100 \mathrm{~cm}^{3}$ mineral oil was determined as 31 and $26.8 \mathrm{mN} / \mathrm{m}$ at 25 and $70{ }^{\circ} \mathrm{C}$, respectively.

The employment of a rotor-stator homogenizer for emulsion mixing reduced the diameters of the droplets since rotor knife spun within the tube, created a pumping action, forcing the sample out through the windows in the tube. The microphotographs of all the emulsion samples are pointed out in Fig. 2. It was observed that all the emulsion droplets were slightly polydisperse. The average diameters of borax and zinc nitrate emulsion droplets were 2.12 and $10 \mu \mathrm{m}$, respectively. When the zinc borate emulsion was heated up to $160{ }^{\circ} \mathrm{C}$ to remove its water content, air bubbles disappeared in the microphotographs. However, it was revealed that the water inside the micelles was not evaporated, hence the droplets kept their stable form. The average diameters of zinc borate emulsion and the emulsion that was heated up to $160{ }^{\circ} \mathrm{C}$ droplets were found as 1.40 and $2.08 \mu \mathrm{m}$, respectively. 
Fig. 2 The microphotographs of a borax emulsion, $\mathbf{b}$ zinc nitrate emulsion, $\mathbf{c}$ zinc borate emulsion, and $\mathbf{d}$ zinc borate emulsion heated up to $160{ }^{\circ} \mathrm{C}$ for $2 \mathrm{~h}$
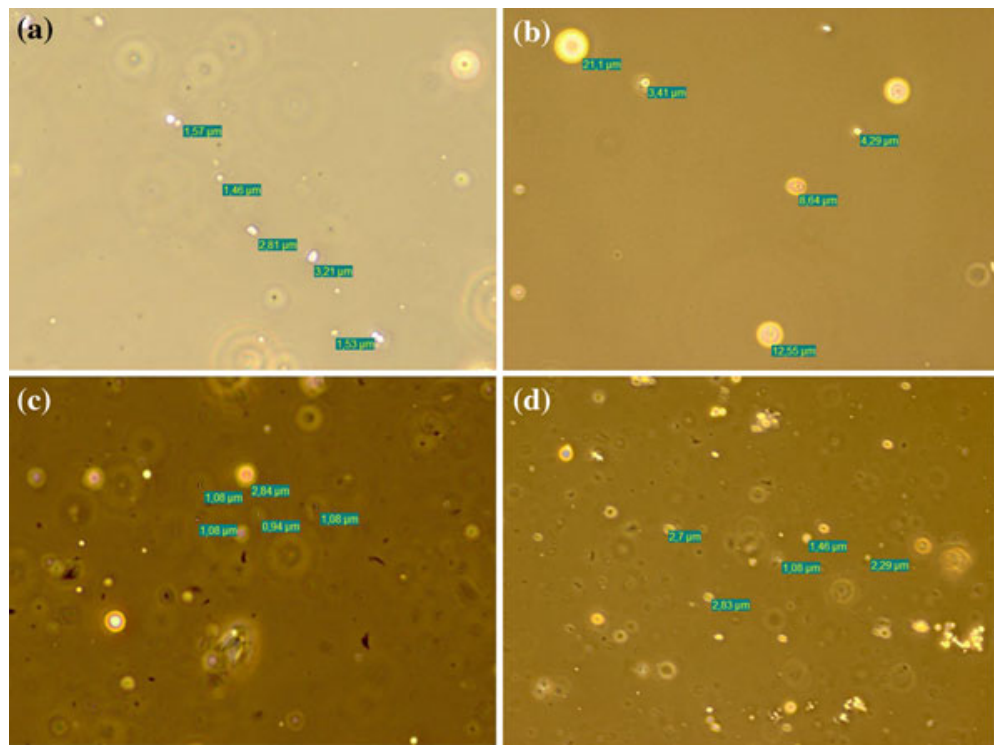

The morphology of sorbitan monostearate and zinc borate

The morphological studies were carried out for both the surfactant and the produced samples by SEM. The morphology of the emulsifier shows that the particles are spherical and they are one within the other. The particle size of the largest particle includes the smaller ones is nearly $500 \mu \mathrm{m}$ and the thickness of the largest particle is nearly $20 \mu \mathrm{m}$ (Fig. 3a). The SEM images of zinc borate produced by inverse emulsion technique and prepared by precipitation technique in the presence of sorbitan monostearate are shown in Fig. $3 \mathrm{~b}$ and c, respectively. The zinc borate particles obtained by mixing two-inverse emulsions had both rod-like and spherical morphologies. The diameters of spherical particles are changing between 20 and $30 \mathrm{~nm}$. On the other hand, zinc borate prepared by precipitation technique in the aqueous medium shows layered structure with long $(20-30 \mu \mathrm{m})$ rods.

The chemical composition of zinc borate

Zinc borate particles produced by inverse emulsion technique and precipitation technique were characterized via CHNS elemental analysis. The results are listed in Table 1. Even if the samples contained the same amount of surfactant, the $\mathrm{C} \%$ of the particles produced by inverse emulsion (12.26\%) was quite higher than that of the other sample since the particles were embedded in the oil, and the washing process was insufficient to remove all the oil. The $\mathrm{H} \%$ of the samples is close to each other and the presence of nitrogen element for the zinc borate produced by inverse emulsion, indicating that the nitrate ion was partially removed from the sample by washing.

The functional groups of sorbitan monostearate and zinc borate

The functional groups of the obtained samples were determined by FTIR. Figure 4 demonstrates FTIR spectra of sorbitan monostearate which was used as a surfactant, zinc borate species produced by inverse emulsion and precipitation technique. FTIR spectrum of the sorbitan monostearate confirmed all the characteristic peaks (at 2850, 2920, 1730, 1467 and 721/cm) of the emulsifier related to partially fatty acid ester of polyol. The zinc borate prepared by precipitation technique in the presence of sorbitan monostearate exhibits both the specific peaks of the surfactant and the zinc borate having seven moles of crystal water $\left(2 \mathrm{ZnO} \cdot 3 \mathrm{~B}_{2} \mathrm{O}_{3} \cdot 7 \mathrm{H}_{2} \mathrm{O}\right)$. The band at $16401 / \mathrm{cm}$ is the bending vibration of water molecules. The characteristic peaks of zinc borate are assigned referring the literature [17, 18]. The bands at 1047 and $14081 / \mathrm{cm}$ are the asymmetric stretching of $\mathrm{B}(4)-\mathrm{O}$ and $\mathrm{B}(3)-\mathrm{O}$, respectively. The decrease in the intensity of the specific peaks of the surfactant (at 2850, $29201 / \mathrm{cm}$ ) implied that the sorbitan monostearate was only partially removed from the samples during the washing process. In FTIR spectrum of the zinc borate prepared by inverse emulsion technique, the bands at $35001 / \mathrm{cm}$ is the stretching of $\mathrm{O}-\mathrm{H}$, whereas, the bands at 2920 and $28521 / \mathrm{cm}$ are $\mathrm{C}-\mathrm{H}$ asymmetric and symmetric stretching peaks of the sorbitan monostearate and mineral oil. Besides them, the asymmetric stretching of $\mathrm{O}-\mathrm{NO}_{2}$ is observed at $13841 / \mathrm{cm}$, proving that these samples contain nitrate ions. This result is consistent with the result obtained from the elemental analysis. 
Fig. 3 The SEM images of zinc borate particles produced by a inverse emulsion technique and $\mathbf{b}$ precipitation technique
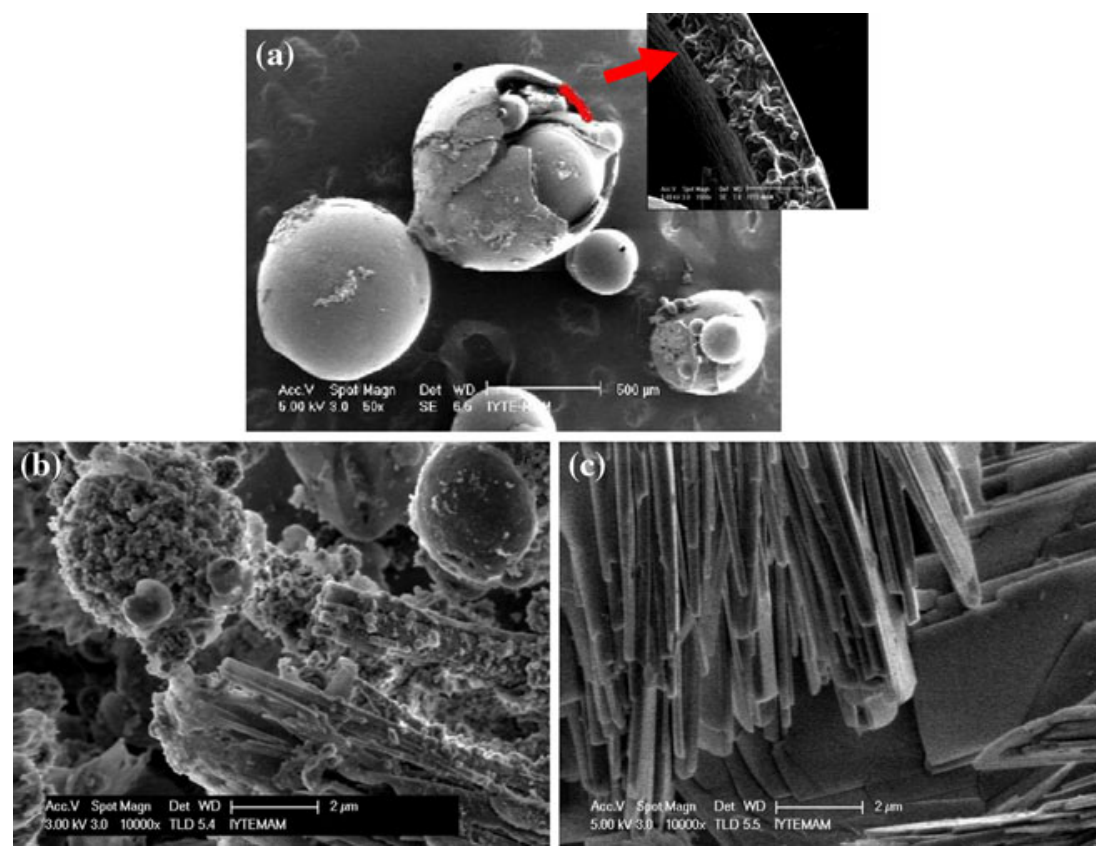

Table 1 The chemical composition of zinc borate particles obtained by CHNS instrument

\begin{tabular}{lll}
\hline Elements & $\begin{array}{l}\text { Zinc borate produced by } \\
\text { reverse emulsion } \\
\text { technique/wt\% }\end{array}$ & $\begin{array}{l}\text { Zinc borate prepared } \\
\text { by precipitation } \\
\text { technique/wt\% }\end{array}$ \\
\hline $\mathrm{C}$ & 12.26 & 1.91 \\
$\mathrm{H}$ & 2.97 & 2.89 \\
$\mathrm{~N}$ & 1.09 & 0.00 \\
\hline
\end{tabular}

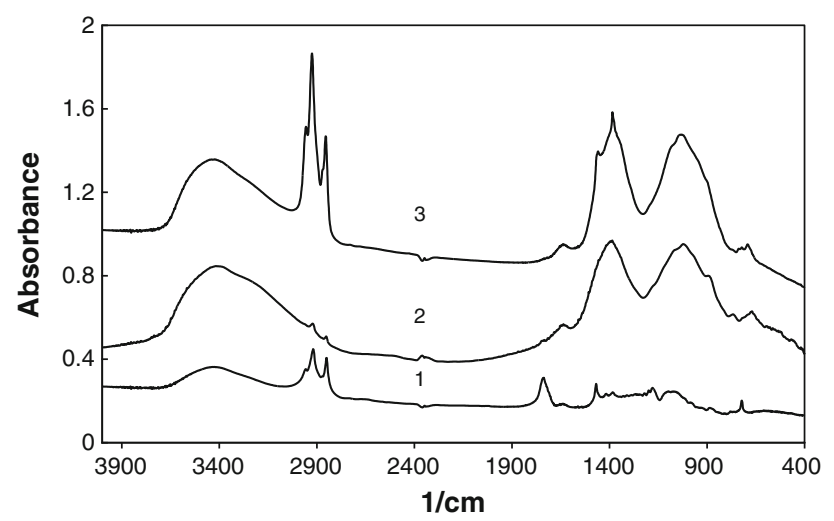

Fig. 4 FTIR spectra of 1 sorbitan monostearate, 2 zinc borate produced by precipitation technique, and 3 zinc borate prepared by inverse emulsion technique

Thermal behavior of sorbitan monostearate and zinc borate

The application areas of zinc borate are changing with its crystal water amount $[2,4]$. Therefore, it is necessary to examine its thermal behavior. Hence, both TG and DSC

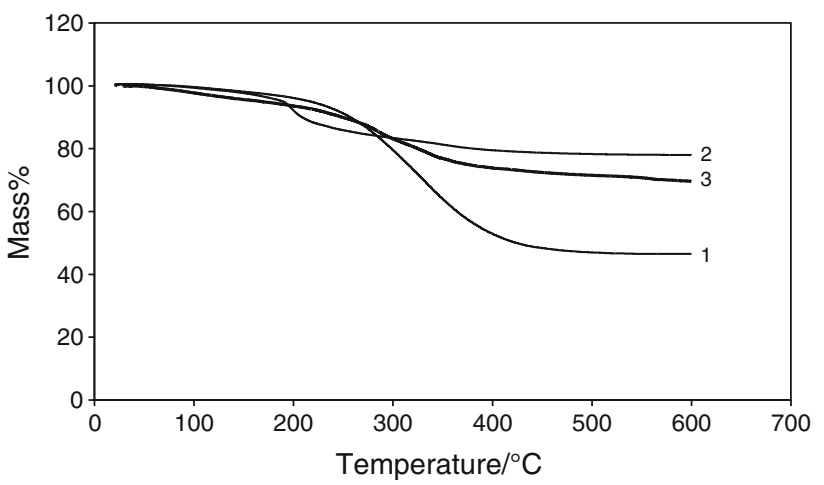

Fig. 5 TG curves of 1 sorbitan monostearate, 2 zinc borate produced by precipitation technique, and 3 zinc borate prepared by inverse emulsion technique

were used to determine their thermal behavior. The TG curves of the zinc borate species and the sorbitan monostearate are shown in Fig. 5. The surfactant starts to loose its mass at $148{ }^{\circ} \mathrm{C}$, whereas, the onset temperatures for the zinc borate particles formed by inverse emulsion and precipitation techniques are 29.5 and $74.62{ }^{\circ} \mathrm{C}$, respectively. According to TG curve of zinc borate prepared by precipitation technique in aqueous medium, the mass loss of the sample is $22.08 \%$ due to the removal of water of crystallization and sorbitan monostearate. In accordance with elemental analysis, the sample contained $2.85 \%$ sorbitan monostearate. Thus, mass loss due to water elimination was $19.23 \%$. This indicated that water content of the sample was higher than the theoretical water amount of $2 \mathrm{ZnO} \cdot 3 \mathrm{~B}_{2} \mathrm{O}_{3} \cdot 3 \mathrm{H}_{2} \mathrm{O}$ which was $12.69 \%$ and it was close to $25 \%$ which indicated the presence of $2 \mathrm{ZnO} \cdot 3 \mathrm{~B}_{2} \mathrm{O}_{3} \cdot 7 \mathrm{H}_{2} \mathrm{O}$. 


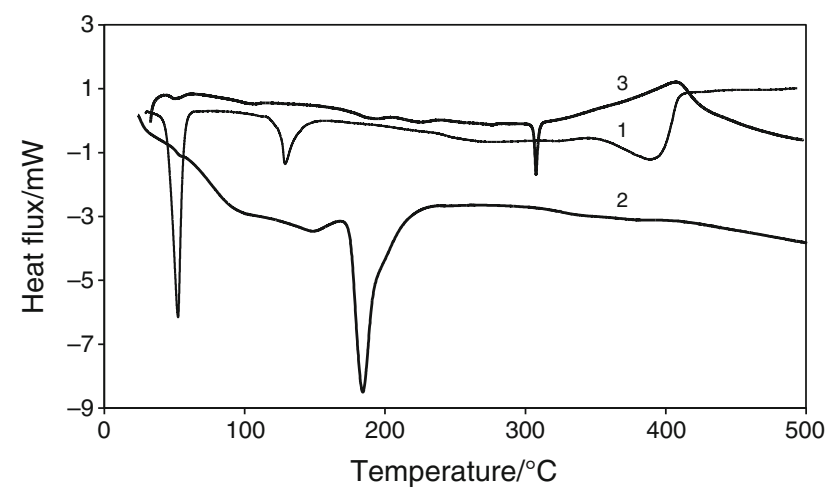

Fig. 6 DSC curves of 1 sorbitan monostearate, 2 zinc borate produced by precipitation technique, and 3 zinc borate prepared by inverse emulsion technique

On the other hand, the mass loss of the sample produced by inverse emulsion technique is $30.42 \%$ at $600{ }^{\circ} \mathrm{C}$. Considering the presence of mineral oil and sorbitan monostearate in the sample, the zinc borate species in this sample was also $2 \mathrm{ZnO} \cdot 3 \mathrm{~B}_{2} \mathrm{O}_{3} \cdot 7 \mathrm{H}_{2} \mathrm{O}$. Moreover, DSC curves of the products and the surfactant are given in Fig. 6. For sorbitan monostearate, the endothermic peak at $50{ }^{\circ} \mathrm{C}$ is observed due to the melting of sorbitan monostearate and the heat of melting is evaluated as $-3.50 \mathrm{~J} / \mathrm{g}$. Also, the peaks between 100 and $200{ }^{\circ} \mathrm{C}$ are related to evaporation of free water. The curves of zinc borate samples show the removal of interstitial water and the dehydration energy for the zinc borate prepared by precipitation technique is $172.22 \mathrm{~J} / \mathrm{g}$.

Crystal structure of sorbitan monostearate and zinc borate

Figure 7 shows the XRD pattern of the zinc borate produced by precipitation technique in aqueous medium. The presence of peaks with high intensity shows that product has a crystalline structure. The major peaks in XRD pattern of zinc borate are observed at $13.07^{\circ}, 17.58^{\circ}, 19.66^{\circ}$,

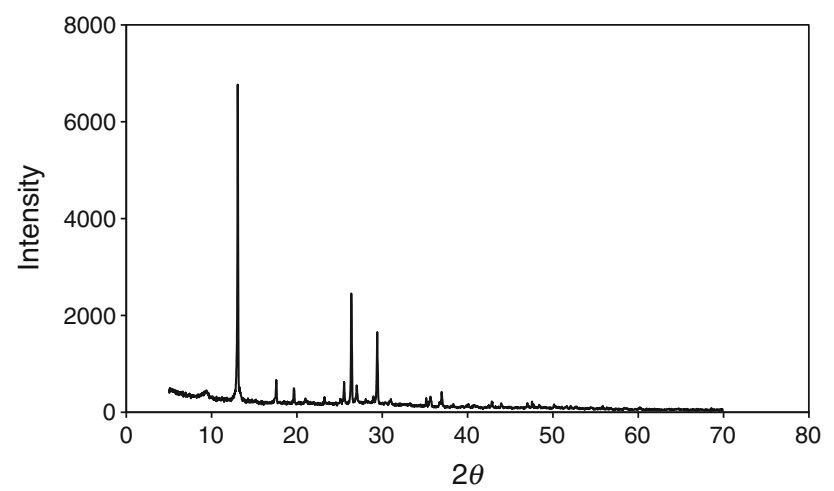

Fig. 7 XRD pattern of zinc borate produced by precipitation technique in aqueous medium $25.54^{\circ}, 26.38^{\circ}, 27.04^{\circ}, 29.42^{\circ}$, and $36.97^{\circ} 2 \theta$ values. When these values were compared with those in the database, it was implied that all the diffraction peaks were perfectly indexed with those of $\mathrm{Zn}\left(\mathrm{B}_{3} \mathrm{O}_{3}(\mathrm{OH})_{5}\right) \cdot \mathrm{H}_{2} \mathrm{O}$ (JPDS PDF File Number 721789). In literature this type of zinc borate was also defined as $2 \mathrm{ZnO} \cdot 3 \mathrm{~B}_{2} \mathrm{O}_{3} \cdot 7 \mathrm{H}_{2} \mathrm{O}$ [4].

Tribological study

The purpose of this part of the study was the evaluation of friction coefficient and wear for the lubricant containing zinc borate and sorbitan monostearate. The tests method covered a procedure for making a determination of antiwear properties of fluid lubricants in sliding contact at constant load $(392 \mathrm{~N})$ considering ASTM D 4172-94 standard. Both the friction coefficient and the friction coefficient of the light neutral oil and the lubricant were investigated. These results are tabulated in Table 2. The friction coefficient was calculated automatically by four ball tester regarding the Eq. 1.

$\mu=222.47 \frac{M_{T}}{P}$,

where $M_{T}$ is the friction torque $(\mathrm{Nm})$ and $P$ is the load $(\mathrm{N})$. The friction coefficient values in Table 2 were imposed by forces acting in the four ball tester and they were the mean value of the friction coefficient during test duration $(1 \mathrm{~h})$ at $75{ }^{\circ} \mathrm{C}$. This table indicated that the better tribological properties were obtained for the lubricant having sorbitan monostearate and zinc borate. Wear scar diameter of oil without additive $(1.402 \mathrm{~mm})$ was reduced to $0.656 \mathrm{~mm}$ when sorbitan monostearate was added to mineral oil. When zinc borate particles $\left(2 \mathrm{ZnO} \cdot 3 \mathrm{~B}_{2} \mathrm{O}_{3} \cdot 7 \mathrm{H}_{2} \mathrm{O}\right)$ obtained by precipitation technique in this study and commercial zinc borate $\left(2 \mathrm{ZnO} \cdot 3 \mathrm{~B}_{2} \mathrm{O}_{3} \cdot 3 \mathrm{H}_{2} \mathrm{O}\right)$ were added to the system containing sorbitan monostearate, wear scar diameter was reduced to 0.639 and $0.650 \mathrm{~mm}$, respectively. The direct employment of inverse emulsion as a lubricant resulted the minimum wear scar diameter $(0.596 \mathrm{~mm})$. The addition of

Table 2 Tribological properties of the ball running in oil with and without additives for load $392 \mathrm{~N}$

\begin{tabular}{lll}
\hline Lubricant types & $\begin{array}{l}\text { Friction } \\
\text { coefficient }\end{array}$ & $\begin{array}{l}\text { Wear scar } \\
\text { diameter/mm }\end{array}$ \\
\hline Oil & 0.099 & 1.402 \\
Oil with sorbitan monostearate & 0.067 & 0.656 \\
$\begin{array}{l}\text { Oil with sorbitan monostearate } \\
\text { and precipitated zinc borate }\end{array}$ & 0.064 & 0.639 \\
$\quad\left(2 \mathrm{ZnO} \cdot 3 \mathrm{H}_{2} \mathrm{O} \cdot 7 \mathrm{H}_{2} \mathrm{O}\right)$ & & \\
$\begin{array}{l}\text { Oil with sorbitan monostearate } \\
\text { and commercial zinc borate } \\
\left(2 \mathrm{ZnO} \cdot 3 \mathrm{~B}_{2} \mathrm{O}_{3} \cdot 3 \mathrm{H}_{2} \mathrm{O}\right)\end{array}$ & 0.066 & 0.650 \\
\begin{tabular}{l} 
Inverse emulsion \\
\hline
\end{tabular} & 0.089 & 0.596 \\
\hline
\end{tabular}


Fig. 8 SEM images of worn surfaces for the balls lubricated a light neutral oil and $\mathbf{b}$ light neutral oil containing sorbitan monostearate and zinc borate
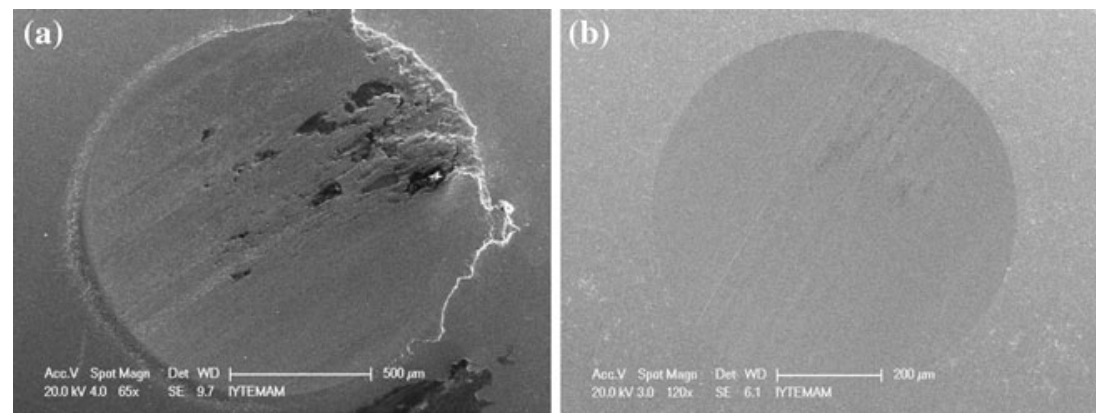

sorbitan monostearate decreased the friction coefficient of the mineral oil from 0.099 to 0.067 . When zinc borate particles $\left(2 \mathrm{ZnO} \cdot 3 \mathrm{~B}_{2} \mathrm{O}_{3} \cdot 7 \mathrm{H}_{2} \mathrm{O}\right)$ obtained by precipitation technique and commercial zinc borate $\left(2 \mathrm{ZnO} \cdot 3 \mathrm{~B}_{2} \mathrm{O}_{3}\right.$. $3 \mathrm{H}_{2} \mathrm{O}$ ) were added to the system containing sorbitan monostearate, friction coefficient was reduced to 0.064 and 0.066 , respectively. However, inverse emulsion showed a reduction in friction coefficient to a smaller extent, it was reduced to 0.089 . In addition to tribological study, wear scar morphology of the ball running in oil with and without additive is presented in Fig. 8. The morphologies of the worn balls showed that the ball lubricated with the light neutral oil containing zinc borate particles and surfactant (Fig. 8b) exhibited much smoother surfaces without severe scuffing.

\section{Conclusions}

In this article, the production of zinc borate that could be used as a lubricant additive was investigated, and both the dispersion and lubricating properties of the zinc borate particles in the oil were studied. The zinc borate particles synthesized with different techniques, the inverse emulsions, and the lubricants were characterized. It was revealed that zinc borate particles prepared by precipitation technique in the aqueous medium showed layered structure with long $(20-30 \mu \mathrm{m})$ rods. Its thermal behavior and crystal structure was consistent with the one having seven moles of crystal water $\left(2 \mathrm{ZnO} \cdot 3 \mathrm{~B}_{2} \mathrm{O}_{3} \cdot 7 \mathrm{H}_{2} \mathrm{O}\right)$. When these particles were used as lubricating oil additives with sorbi$\tan$ monostearate, it was observed that they could effectively improve the lubricating property of the light neutral oil in the same extent with commercial $2 \mathrm{ZnO} \cdot 3 \mathrm{~B}_{2} \mathrm{O}_{3} \cdot 3 \mathrm{H}_{2} \mathrm{O}$. Zinc borate $\left(2 \mathrm{ZnO} \cdot 3 \mathrm{~B}_{2} \mathrm{O}_{3} \cdot 7 \mathrm{H}_{2} \mathrm{O}\right)$ produced by precipitation decreased the wear scar diameter from 1.402 to $0.639 \mathrm{~mm}$ and the friction coefficient from 0.099 to 0.064 . The spherical and rod shaped particles formed in inverse emulsions were also coated with sorbitan monostearate. The highlighted part of the study was using inverse emulsion as a lubricant after removing its water content by heating. The inverse emulsion was particularly effective in decreasing wear scar diameter by lowering it to 0.596 . This production process required the synthesis of nano particles within the continuous phase; hence the problems related to nanoparticle production such as separation of particles from the solution, dispersion of the particles in the oil were overcome.

Acknowledgements The authors acknowledge the financial support from The Scientific and Technical Research Council of Turkey (TÜBITAK) (project number: 105M358), OPET Petrolcülük A.Ş. for providing tribological properties of zinc borate lubricants and Izmir Institute of Technology, Biotechnology and Bioengineering Central Research Laboratories for the optical microscopy studies.

\section{References}

1. Tian Y, He Y, Yu L, Deng Y, Zheng Y, Sun F, Liu Z, Wang Z. In situ and one-step synthesis of hydrophobic zinc borate nanoplatelets. Colloids Surf A. 2008;312:99-103.

2. Köytepe S, Vural S, Seçkin T. Molecular design of nanometric zinc borate-containing polyimide as a route to flame retardant materials. Mater Res Bull. 2009;44:369-76.

3. Dong JX, Hu ZS. A study of the anti-wear and friction-reducing properties of the lubricant additive, nanometer zinc borate. Tribol Int. 1998;3:219-23.

4. Eltepe HE, Balköse D, Ülkü S. Effect of temperature and time on zinc borate species formed from zinc oxide and boric acid in aqueous medium. Ind Eng Chem Res. 2007;46:2367-71.

5. Erdoğdu CA, Atakul S, Balköse D, Ülkü S. Development of synergistic heat stabilizers for PVC from zinc borate-zinc phosphate. Chem Eng Commun. 2009;196:148-60.

6. Capek I. Preparation of metal nanoparticles in water-in-oil (w/o) microemulsions. Adv Colloid Interface Sci. 2004;110:49-74.

7. Shi J, Weweij H. Synthesis and purification of oxide nanoparticle dispersions by modified emulsion precipitation. Langmiur. 2005;2:5570-5.

8. Yu Z, Sun Y, Wei W, Lu L, Wang X. Preparation of $\mathrm{NdCrO}_{3}$ nanoparticles and their catalytic activity in the thermal decomposition of ammonium perchlorate by DSC/TG-MS. J Therm Anal Calorim. 2009;97:903-9.

9. Bakunin VN, Suslov Ay, Kuzmina GN, Prenago OP. Synthesis and application of inorganic nanoparticles as lubricant components-a review. J Nanopart Res. 2004;6:273-84.

10. Tai CY, Chen CK. Particle morphology, habit, and size control of $\mathrm{CaCO}_{3}$ using reverse microemulsion technique. Chem Eng Sci. 2008;63:3632-42.

11. Sharma BK, Rashid U, Anwar F, Erhan SZ. Lubricant properties of Moringa oil using thermal and tribological techniques. J Therm Anal Calorim. 2009;96:999-1008. 
12. Hu ZS, Lai R, Lou F, Wang LG, Chen ZL, Chen GX, Dong JX. Preparation and tribological properties of nanometer magnesium borate as lubricating oil additive. Wear. 2001;252:370-4.

13. Hu ZS, Dong JX. Study on antiwear and reducing friction additive of nanometer titanium borate. Wear. 1998;216:87-91.

14. Hu ZS, Dong JX, Chen GX, He JZ. Preparation and tribological properties of nanoparticle lanthanum borate. Wear. 2000;243:43-7.

15. Wasilewski T, Sulek MW. Paraffin oil solutions of the mixture of sorbitan monolaurate-ethoxylated sorbitan monolaurate as lubricants. Wear. 2006;261:230-4.
16. Hu ZS, Dong JX, Chen GX. Replacing solvent drying technique for nanometer particle preparation. J Colloid Interface Sci. 1998;208:367-72.

17. Goa YH, Liu ZH, Wang XL. Hydrothermal synthesis and thermodynamic properties of $2 \mathrm{ZnO} \cdot 3 \mathrm{~B}_{2} \mathrm{O}_{3} \cdot 3 \mathrm{H}_{2} \mathrm{O}$. J Chem Thermodyn. 2009;41:775-8.

18. Jun L, Shupping X, Shiyang G. FT-IR and raman spectroscopic study of hydrated borates. Spectrochim Acta A Mol Biomol Spectrosc. 1995;51:519-32. 